\title{
Mutually inclusive mechanisms of drought-induced tree mortality
}

Peter Hajek ${ }^{1, * \#, ~ R o m a n ~ M . ~ L i n k ~}{ }^{2, *, \#}$, Charles Nock ${ }^{1,3}$, Jürgen Bauhus ${ }^{4}$, Tobias Gebauer ${ }^{1}$, Arthur Gessler $^{5,6}$, Kyle Kovach ${ }^{1}$, Christian Messier ${ }^{7,8}$, Alain Paquette ${ }^{7}$, Matthias Saurer ${ }^{5}$, Michael Scherer-Lorenzen $^{1}$, Laura Rose ${ }^{1,9}$, Bernhard Schuldt ${ }^{2}$

${ }^{1}$ University of Freiburg, Geobotany, Schänzlestr. 1, 79104 Freiburg, Germany

${ }^{2}$ University of Würzburg, Julius-von-Sachs-Institute of Biological Sciences, Chair of Ecophysiology and Vegetation Ecology, Julius-von-Sachs-Platz 3, 97082 Würzburg, Germany

${ }^{3}$ University of Alberta, Department of Renewable Resources, Edmonton, AB, Canada

${ }^{4}$ University of Freiburg, Chair of Silviculture, Tennenbacherstr. 4, 79106 Freiburg, Germany

${ }^{5}$ Swiss Federal Institute for Forest, Snow and Landscape Research, Forest Dynamics, Zürcherstrasse 111, 8903 Birmensdorf, Switzerland

${ }^{6}$ ETH Zurich, Institute of Terrestrial Ecosystems, Universitätsstrasse 14, 8092 Zurich, Switzerland

${ }^{7}$ Université du Québec à Montréal, Center for Forest Research, Montréal, QC, Canada

${ }^{8}$ University of Quebec in Outaouais (UQO), Institut des Sciences de la Forêt Tempérée (ISFORT), Gatineau, QC, Canada

${ }^{9}$ Station d'Ecologie Théorique et Expérimentale, UMR 5321 (CNRS - Université Toulouse III), 2 route du CNRS, 09200 Moulis, France

* first and second author contributed equally

\#Correspondence: peter.hajek@biologie.uni-freiburg.de; roman.link@plant-ecology.de

Keywords: Climate change, embolism resistance, hierarchical Bayesian modelling, hydraulic failure, neighbourhood interactions, IDENT, non-structural carbohydrate dynamics, pest infestation, TreeDivNet. 


\begin{abstract}
An extreme summer drought caused unprecedented tree dieback across Central Europe in 2018, highlighting the need for a better mechanistic understanding of drought-induced tree mortality. While numerous physiological risk factors have been identified, the principal mechanisms, hydraulic failure and carbon starvation, are still debated. We studied 9,435 trees from 12 temperate species planted in a diversity experiment in 2013 to assess how hydraulic traits, carbon dynamics, pest infestation, tree height and neighbourhood competition influence individual mortality risk. We observed a reduced mortality risk for trees with wider hydraulic safety margins, while a rising sugar fraction of the non-structural carbohydrate pool and bark beetle infestation were associated with higher risk. Taller trees had a lower mortality risk. The sign and magnitude of neighbourhood effects on mortality risk depended on the species-identity of the involved trees, with most species having beneficial and some having deleterious effects on their neighbours. While severe tissue dehydration causing hydraulic failure precedes drought-induced tree mortality, we show that the probability of this event depends on a series of mutually inclusive processes including pest infestation and starch depletion for osmotic adjustment, and is modulated by the size and species identity of a tree and its neighbours.
\end{abstract}




\section{Introduction}

Worldwide, forests are exposed to rises in temperature, atmospheric vapour pressure deficit and intensity and frequency of severe drought events (Dai 2013; Yuan et al. 2019; Zhou et al. 2019). As a consequence, large-scale tree mortality events are documented for all forest biomes (Allen et al. 2015; Hartmann et al. 2018; Senf et al. 2018; Schuldt et al. 2020). Challenges in forecasting the impacts of drought-related tree mortality based on the structure and composition of forests highlight the need for a robust mechanistic understanding of the processes involved (Choat et al. 2018; Brodribb et al. 2020).

Two interrelated physiological mechanisms are central for drought-induced tree mortality: hydraulic failure, which is the partial or complete loss of xylem functionality due to embolism formation, and carbon starvation, the depletion of non-structural carbohydrates (NSC) due to negative drought impacts on photosynthesis (McDowell et al. 2008). While there is clear evidence that hydraulic failure is a universal component of the processes preceding tree death under drought (Rowland et al. 2015; Anderegg et al. 2016; Adams et al. 2017; Correia et al. 2019; Powers et al. 2020; Li et al. 2020), the role of NSC reserves in these processes is still debated (Adams et al. 2017; Blackman et al. 2019; Kannenberg \& Phillips 2020; O`Brien et al. 2020). Both processes interact with antagonistic biotic agent demographics (McDowell et al. 2008, 2011), as drought effects on the water and carbon balance may additionally predispose trees to pathogen or insect attacks (Raffa et al. 2008; Sturrock et al. 2011; Hart et al. 2014; Huang et al. 2020), exacerbating climate-driven forest mortality (McDowell et al. 2013, 2020; Seidl et al. 2017).

Many risk factors have been associated with drought-induced mortality (O'Brien et al. 2017). Specifically, increasing tree size is often found to increase drought vulnerability (Peng et al. 2011; Bennett et al. 2015; O’Brien et al. 2017; Stovall et al. 2019). Further, water shortage may intensify interspecific tree competition depending on species-specific water use behaviour and above- and below-ground niche partitioning (Ammer 2019; Grossiord 2019), thus affecting 
individual mortality risk via variation in local neighbourhood composition (Vitali et al. 2018; Fichtner et al. 2017, 2020).

In the recent past, several distinct mechanisms of drought-induced mortality have been proposed for a variety of tree species in different biomes (Adams et al. 2017; O`Brien et al. 2017; Choat et al. 2018; Brodribb et al. 2020). Mechanistic insight advancing future processbased models is most likely to result from research that accounts for the multitude of simultaneous processes at play during tree death under drought (McDowell et al. 2019). Consequently, field-based studies that jointly analyse multiple potential causes of droughtinduced tree mortality across a range of functionally different tree species are urgently needed. In 2018, Central Europe experienced an extreme summer drought, followed by a non-typical dry winter and spring (Hari et al. 2020). This global-change type drought event resulted in the highest average growing season temperature and vapour pressure deficit ever recorded $\left(3.3^{\circ} \mathrm{C}\right.$ and 3.2 $\mathrm{hPa}$ above the long-term average for the reference period from 1961-1990, respectively) and caused unprecedented drought-induced tree mortality in many species (Schuldt et al. 2020). We used observations from 9,435 trees belonging to six angiosperm and six coniferous species from Europe and North America grown in a young tree diversity and nutrient enrichment experiment established in 2013 in Southern Germany (Wein et al. 2016) to try to untangle the complexity of possible mechanisms explaining drought-induced mortality in trees. Based on a Bayesian hierarchical modelling approach, we predicted the individual mortality risk following the drought using data on hydraulic traits, carbon dynamics, pest infestation, tree height and interactions with neighbouring trees. We ask whether (i) a tree species' susceptibility to drought-induced mortality depends on both hydraulic traits and NSC dynamics, and whether (ii) the probability of dying on the individual level is modulated by tree height and the influence of biotic (pest infestation and interaction with neighbour trees) and abiotic (fertilisation and environmental) factors. 
Table 1. Properties of the 12 studied species. Given are the acronyms, species names, origin (EU: Europe; NA: North America), group (angio- or gymnosperm), pre-drought height, stem diameter at $10 \mathrm{~cm}$ height (Dia.), xylem pressure at 50\% and $88 \%$ loss of conductivity $\left(P_{50}\right.$ and $\left.P_{88}\right)$, midday water potential $\left(\Psi_{\mathrm{md}}\right)$, change in leaf NSC sugar fraction over the growing period ( $\Delta$ sugar), proportion of trees with visible beetle damage ( $\%$ of central trees), proportion of trees with neighbours infested by beetles ( $\%$ of central trees), and observed mortality (\% of central trees). Given values are mean \pm SE. $P_{50}$ and $P_{88}$-values for the two Quercus species were taken from Lobo et al. (2018).

\begin{tabular}{|c|c|c|c|c|c|c|c|c|c|c|c|c|c|}
\hline Acronym & Species & Origin & Group & Height (m) & Dia. $(\mathbf{m m})$ & $\mathbf{P}_{50}(\mathrm{MPa})$ & $\mathrm{P}_{88}$ (MPa) & $\Psi_{\text {md }}(\mathrm{MPa})$ & HSM(MPa) & $\Delta$ sugar $(\%)$ & B. $(\%)$ & N.w.B. (\%) & $\operatorname{Mort}_{\text {obs }}(\%)$ \\
\hline ACPL & Acer platanoides & $\mathrm{EU}$ & Angio & $4.30 \pm 0.04$ & $33.0 \pm 0.4$ & $-4.56 \pm 0.16$ & $-5.27 \pm 0.12$ & $-2.50 \pm 0.05$ & $2.77 \pm 0.06$ & $-21.47 \pm 7.86$ & 0.0 & 8.8 & 1.6 \\
\hline ACSA & Acer saccharum & NA & Angio & $4.72 \pm 0.07$ & $30.1 \pm 0.6$ & $-4.22 \pm 0.11$ & $-4.61 \pm 0.13$ & $-2.83 \pm 0.25$ & $1.78 \pm 0.25$ & $-24.31 \pm 7.48$ & 0.0 & 3.8 & 0.6 \\
\hline BEPA & Betula papyrifera & NA & Angio & $4.92 \pm 0.05$ & $43.0 \pm 0.7$ & $-2.29 \pm 0.03$ & $-2.42 \pm 0.04$ & $-1.66 \pm 0.17$ & $0.63 \pm 0.17$ & $3.56 \pm 2.14$ & 0.0 & 0.3 & 56.1 \\
\hline BEPE & Betula pendula & $\mathrm{EU}$ & Angio & $5.26 \pm 0.03$ & $50.0 \pm 0.5$ & $-2.33 \pm 0.04$ & $-2.47 \pm 0.05$ & $-1.30 \pm 0.05$ & $1.02 \pm 0.05$ & $16.16 \pm 10.4$ & 0.2 & 2.4 & 43.0 \\
\hline LADE & Larix decidua & $\mathrm{EU}$ & Gymno & $3.75 \pm 0.04$ & $39.8 \pm 0.5$ & $-3.63 \pm 0.07$ & $-4.05 \pm 0.10$ & $-1.98 \pm 0.09$ & $1.65 \pm 0.09$ & $17.00 \pm 3.08$ & 15.8 & 29.1 & 56.1 \\
\hline LALA & Larix laricina & NA & Gymno & $3.18 \pm 0.07$ & $27.7 \pm 0.8$ & $-3.44 \pm 0.05$ & $-3.85 \pm 0.09$ & $-2.01 \pm 0.05$ & $1.43 \pm 0.05$ & $-3.43 \pm 7.75$ & 0.0 & 3.6 & 79.5 \\
\hline PIAB & Picea abies & $\mathrm{EU}$ & Gymno & $2.06 \pm 0.02$ & $27.1 \pm 0.2$ & $-3.77 \pm 0.10$ & $-4.53 \pm 0.17$ & $-2.11 \pm 0.31$ & $1.67 \pm 0.31$ & $-19.82 \pm 5.37$ & 12.8 & 21.4 & 48.4 \\
\hline PIPU & Picea pungens & NA & Gymno & $1.16 \pm 0.02$ & $22.7 \pm 0.4$ & $-4.04 \pm 0.07$ & $-4.84 \pm 0.11$ & $-1.96 \pm 0.04$ & $2.08 \pm 0.04$ & $-10.06 \pm 5.63$ & 1.4 & 9.8 & 33.4 \\
\hline PIST & Pinus strobus & NA & Gymno & $2.52 \pm 0.05$ & $33.0 \pm 0.6$ & $-2.97 \pm 0.03$ & $-3.26 \pm 0.04$ & $-1.76 \pm 0.05$ & $1.21 \pm 0.05$ & $-33.19 \pm 1.75$ & 0.0 & 2.8 & 22.3 \\
\hline PISY & Pinus sylvestris & $\mathrm{EU}$ & Gymno & $2.70 \pm 0.03$ & $36.8 \pm 0.5$ & $-3.10 \pm 0.05$ & $-3.57 \pm 0.04$ & $-1.84 \pm 0.12$ & $1.26 \pm 0.12$ & $-1.48 \pm 4.71$ & 1.4 & 11.2 & 35.4 \\
\hline QURO & Quercus robur & $\mathrm{EU}$ & Angio & $2.21 \pm 0.03$ & $18.5 \pm 0.3$ & $-4.74 \pm 0.09$ & $-5.66 \pm 0.09$ & $-3.00 \pm 0.03$ & $2.66 \pm 0.10$ & $0.00 \pm 0.00$ & 0.1 & 5.9 & 27.1 \\
\hline QURU & Quercus rubra & NA & Angio & $3.54 \pm 0.08$ & $24.3 \pm 0.6$ & $-4.43 \pm 0.25$ & $-6.72 \pm 0.29$ & $-3.07 \pm 0.09$ & $3.65 \pm 0.30$ & $-14.05 \pm 11.2$ & 0.0 & 6.6 & 3.0 \\
\hline
\end{tabular}




\section{Results and discussion}

\section{Cross-species patterns of drought-induced tree mortality rates}

In response to the anomalous severe drought of the year 2018 and the prolonged dry conditions that followed throughout the winter and spring of $2019,34 \%$ of the 9,435 trees present in our experimental plantation died. Tree mortality increased dramatically compared to a total loss of 9\% of trees between 2013 and early 2018 (see Methods). Mortality rates varied strongly across the 12 studied species, ranging from $0.6 \%$ for A. saccharum to $79.5 \%$ for L. laricina (Table 1, Fig. 1). The average probability of dying predicted by our model closely reflected the specieslevel mortality rates observed in the field (Fig. 1). Our model reached full convergence (Table S2.1) and explained $51.8 \%$ of the variance in the observed individual mortality (Fig. 2). Mortality rates were credibly elevated over the average mortality rate (i.e. their $95 \%$ highest posterior density interval (HDI) excluded the overall average) for Larix spp., Betula spp. and P. abies, while they were much lower specifically for Acer spp. and $Q$. rubra (credibly below $10 \%$ in all three cases).

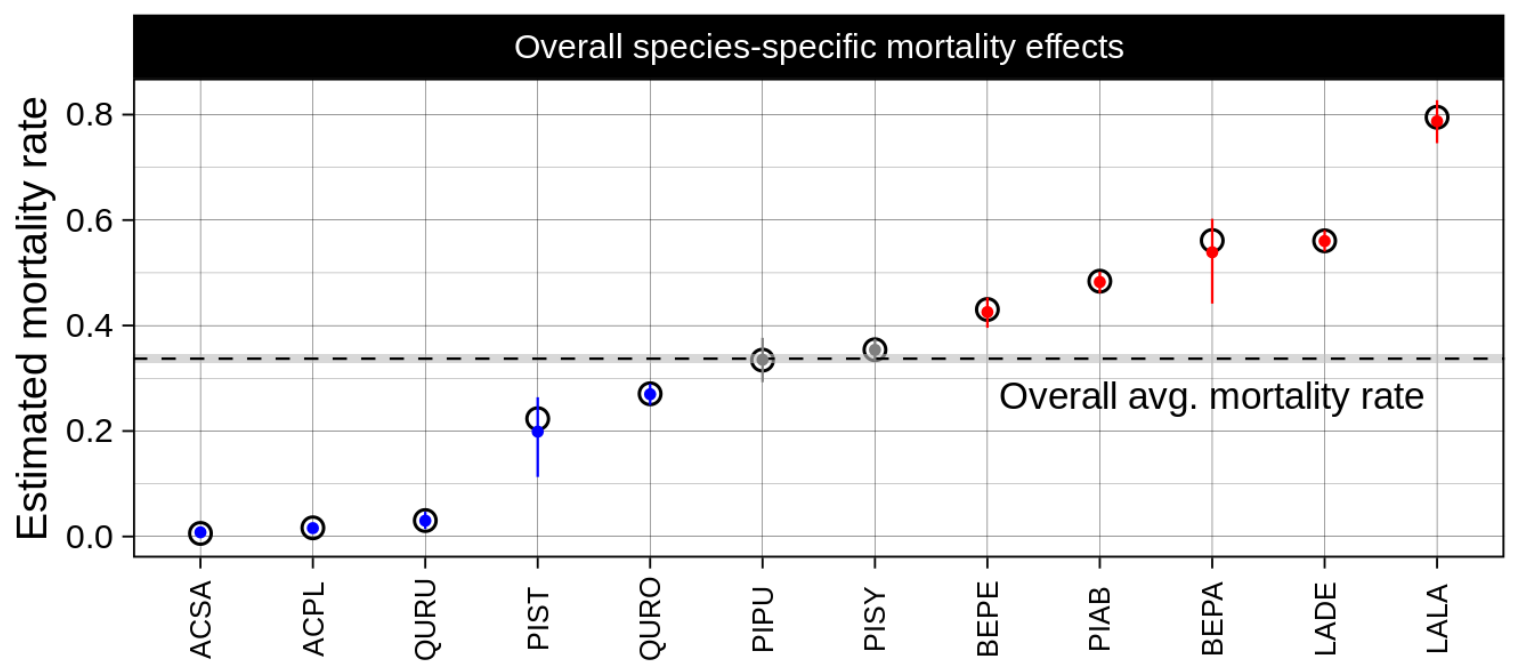

Fig. 1. Average estimated mortality rates for each species ordered by magnitude (posterior mean $\pm 95 \%$ highest posterior density interval (HDI)). Dashed line with grey ribbon: overall predicted average $\pm 95 \%$ HDI. Red: risk credibly elevated over average level; blue: risk credibly below average; grey: not credibly different from average. For species acronyms, see Table 1. Black circles: observed average mortality rates (mismatch for P. strobus, B. papyrifera and L. laricina results from misclassification). 


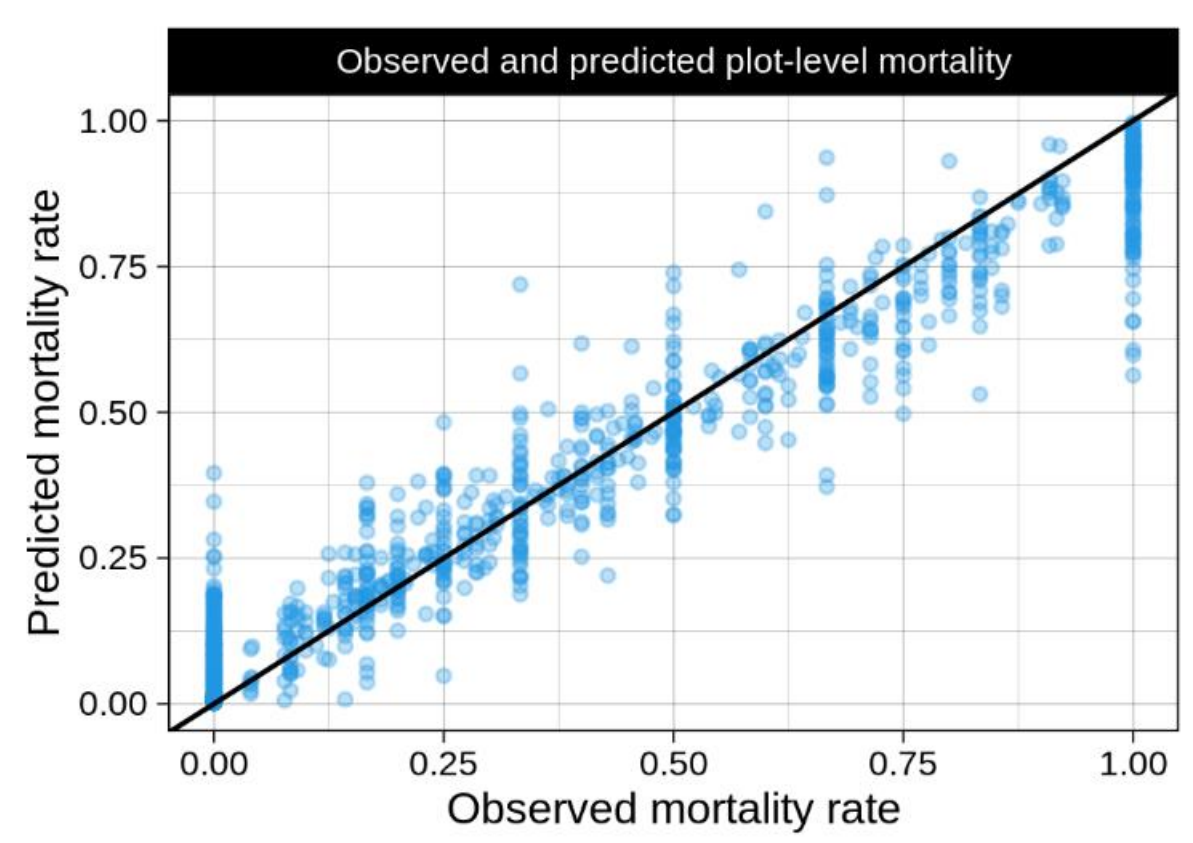

Fig. 2. Posterior mean species-wise plot average mortality rate vs. observed proportion of dead trees per species and plot (explained variance in individual tree mortality: 51.8\%).

\section{Hydraulic safety margins and non-structural carbohydrates}

Both hydraulic traits and carbohydrate dynamics differed considerably among species, with observed hydraulic safety margins (HSM) ranging from 0.63 to $3.65 \mathrm{MPa}$, and changes in the fraction of soluble sugars (glucose, fructose and sucrose) to total leaf NSC ( $\left.\Delta_{\text {sugar }}\right)$ over the growing season ranging from -33.2 to $+17.0 \%$ (Table 1). An increase in relative leaf sugar content is indicative of starch depletion and higher need of soluble sugars for osmotic adjustment (Hsiao 1976; Thalmann \& Santelia 2017). We detected credible effects (i.e. 95\% HDI excluding zero) of both HSM and $\Delta_{\text {sugar }}$ on the mortality risk, with species with a wider HSM being at lower risk, and species with a more pronounced increase in relative leaf sugar content dying at higher rates (Fig. 3, Fig. 4, Table S2.1). This suggests that drought-induced mortality in trees is jointly influenced by both hydraulic failure and carbon starvation (McDowell et al. 2011).

The lower mortality we observed in species with wider HSMs is in line with reported crossspecies patterns in all forested biomes (Anderegg et al. 2016) and supports the hypothesis that 

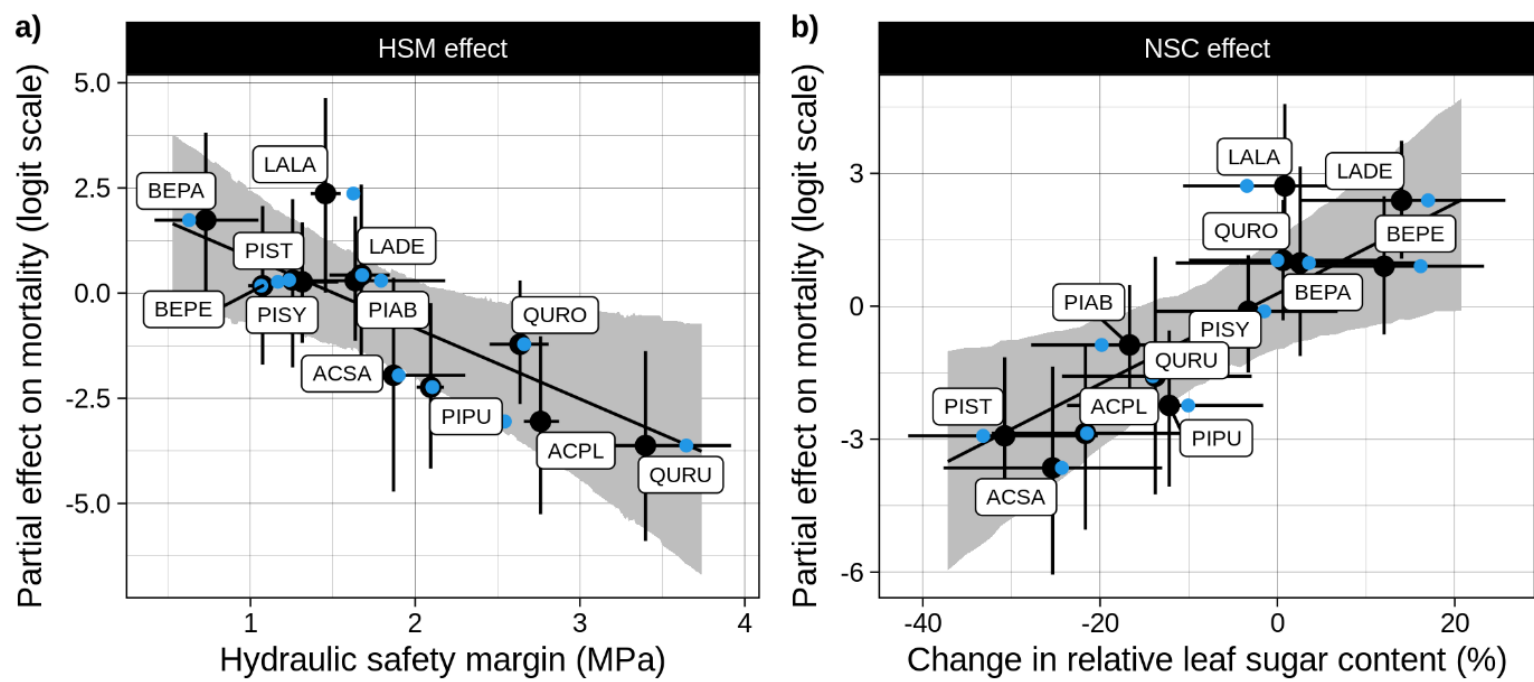

Fig. 3. Partial effects for the species level effects of a) hydraulic safety margins and b) change in relative leaf sugar content (indicative of starch depletion) on the mortality risk. Black line with grey bands: posterior mean $\pm 95 \%$ HDI. For species acronyms, see Table 1 . Blue points: average observed values; black points: estimates $\pm 95 \%$ HDI.

hydraulic traits capture proximate mechanisms determining tree death (Adams et al. 2017). After the loss of hydraulic connectivity at the soil-root-interface during prolonged drought (Carminati \& Javaux 2020), the amount of internally stored water and its loss via leaky stomata, the cuticle and the bark determine the timing of lethal tissue dehydration (Blackman et al. 2016; Choat et al. 2018; Duursma et al. 2019). Reaching critical desiccation thresholds may thus mark the final step in the dying process of trees rather than being the cause of death.

In contrast to hydraulic failure, the diverse physiological responses affecting NSC reserves at the time of death indicate that carbon starvation is not a universal phenomenon of tree death during drought events (Hartmann et al. 2013; Adams et al. 2017; Dai et al. 2018; O’Brien et al. 2020). However, partial canopy dieback and/or the loss of xylem functionality will result in a reduction of leaf area, which in turn affects whole-plant net photosynthesis and carbon allocation in post-drought years. Recent evidence suggests that embolism repair under tension, i.e. restoration of xylem functionality concurrent with transpiration, is either a rare phenomenon or even completely absent in many tree species (Charrier et al. 2016; Choat et al. 2019; Duan 


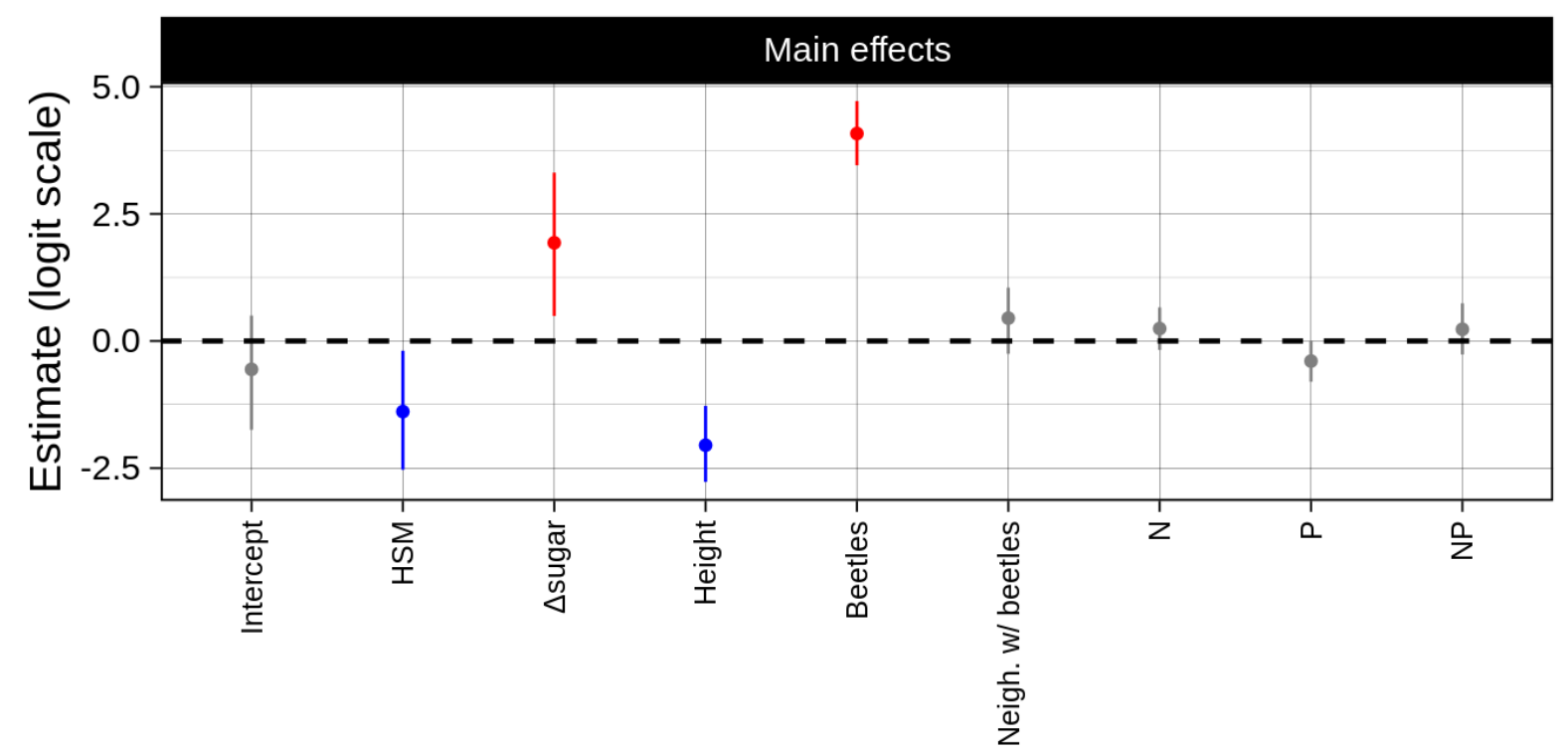

Fig. 4. Estimated main effects on mortality on the logit scale (posterior mean $\pm 95 \%$ HDI). Blue: credibly reduced risk; red: credibly elevated risk; grey: no credible effect on mortality. HSM: hydraulic safety margins. Compare Fig. S2.2 for species-specific effects.

et al. 2019; Rehschuh et al. 2020; but see Klein et al. 2018; McDowell et al. 2019). This might explain commonly observed legacy effects of reduced vigour and increased mortality rates up to several decades after a drought event (Cailleret et al. 2017; Timofeeva et al. 2017; Trugman et al. 2018), as well as different patterns of post-drought recovery ( $\mathrm{Li}$ et al. 2020). The mechanisms governing drought-induced tree mortality and recovery might therefore be closely linked to carbon dynamics (Trugman et al. 2018). Noteworthily, Larix spp. and Betula spp., two of the most strongly drought-affected genera, showed signs of leaf browning and defoliation already in early July 2018. While leaf shedding can mitigate drought effects on a plants' water balance via reduction of the transpiring surface (Blackman et al. 2019), the high $\Delta_{\text {sugar }}$ in these genera (Table 1) indicates that the reduced carbon gain caused by this strategy may have contributed to their high mortality rates.

Both access to carbohydrate reserves and their utilization rate have been reported to be controlled by water availability (Sevanto et al. 2014), providing evidence that carbohydrate use is controlled by the functionality of the water transport system (Atkin \& Macherel 2009) rather 
than by photosynthetic carbon gain. This is consistent with a hydraulic constraint on NSC consumption (McDowell \& Sevanto 2010; Sala et al. 2010; McDowell et al. 2011). The role of carbohydrates in osmotic adjustment constitutes a central link between carbon metabolism and hydraulic functioning (Pantin et al. 2013; Merchant 2014). In the absence of drought, experimental manipulation of NSC storage can affect osmotic regulation and shift the turgor loss point towards substantially less negative water potentials (Sapes et al. 2020). This is consistent with a recent meta-analysis providing evidence for a decrease in starch and rise in soluble sugars over the course of extreme drought events (He et al. 2020). The observed decrease of the relative starch fraction in the more drought-affected species is a strong indication for starch-to-sugar conversion to meet the trees' metabolic and osmoregulatory demands during drought. The use of stored starch to produce osmotically active sugars indicates that the supply with recent assimilates was not sufficient for osmotic regulation. For example, extreme drought led to a strong conversion of starch to sugars in needles and other plant tissues in Scots pine before a mortality event, while the starch-to-sugar ratios did not change during a milder and non-lethal drought (Schönbeck et al. 2020). The use of local storage for osmotic regulation thus seems to be an indicator of carbon starvation and does ensure survival under extreme drought. If plants indeed increase the concentrations of soluble sugars to maintain turgor under declining water potentials, the NSC depletion often seen in dying trees (Adams et al. 2017) is likely to act as an underlying cause of hydraulic failure rather than a separate process. This may explain the divergent explanations of the proximate causes of plant death under drought.

\section{Tree size effects}

In addition to the species-level effects of HSM and NSC dynamics, our model identified a positive within-species effect of tree height on the survival of all species except for $Q$. rubra, though the magnitude of that height effect varied strongly among species (Fig. 4; Fig. S2.2). 
This finding is in contrast to mounting evidence that larger trees tend to be more susceptible to drought-induced tree mortality across biomes (Phillips et al. 2010; Lindenmayer et al. 2012; Bennett et al. 2015; Grote et al. 2016; Olson et al. 2018; Stovall et al. 2019, 2020), although some authors report opposite patterns (Van Mantgem et al. 2009; Peng et al. 2011). This apparent contradiction might result because studies reporting higher mortality for the largest trees usually focus on adult trees in mature forest stands, where crown exposure (Stovall et al. 2019) and path length-related constraints on water transport (Ryan \& Yoder 1997; West et al. 1999) are more relevant. Our analysis, in turn, was based on densely spaced and young trees (planted in 2013 at the age of 1-3 years) with limited variation in tree height (Table 1). Under these circumstances, negative density-dependent drivers of mortality are likely to dominate (Crouchet et al. 2019), disproportionally affecting smaller, competitively supressed tree individuals via self- and alien-thinning (Kohyama 1994, Pretzsch \& Forrester 2017). A potential explanation for the competitive advantage of larger trees in the experiment is their extensive root system and better access to deep soil water, particularly during periods of water shortage (Ledo et al. 2018).

\section{Bark beetle effects on conifers}

Individuals diagnosed with bark beetle infestation in 2018 had a much higher probability of dying (Fig. 4), consistent with a drought-driven predisposition for biotic attacks (McDowell et al. 2011). The prevalence of bark beetles differed greatly between species, with strong outbreaks only for P. abies and L. decidua (Table 1). Most likely, a decline in resin exudation and thus defence capability caused by the reduction of relative tissue water content made $P$. abies vulnerable to insect infestation (Netherer et al. 2015). Despite the low overall prevalence, the infested individuals among the native conifers $P$. abies, L. decidua and P. sylvestris died with high probability. As bark beetles cause physical damage to the phloem and xylem that is likely to affect both carbon metabolism and xylem water transport, their role for plant death 
cannot be understood without acknowledging its link to other processes driving droughtinduced mortality (McDowell et al. 2008, 2011). Since both healthy and infested trees died during the drought event while a number of infested trees were able to survive, biotic attack was unlikely to be the main driver of mortality in the affected species. Therefore, pest infestations should rather be interpreted as an additional stressor amplifying the risk of death by other causes.

The presence of bark beetles in neighbouring trees had no overall effect on mortality (Fig. 4), and on species level only affected $P$. abies, the native species that suffered the strongest beetle infestation (Fig. S2.2). While neighbourhood effects can profoundly impact the predisposition to insect herbivory (Castagneyrol et al. 2018), the low influence in our study may be related to the timing of the assessment of pest infestation in late 2018, when the drought and associated insect outbreaks hat likely already run its course and further spread was unlikely.

\section{Interactions with neighbour trees}

Neighbourhood tree species diversity might help to mitigate drought impacts due to complementarity effects, i.e. temporal or spatial resource partitioning that results in higher water availability in mixed than in pure communities, or facilitation, i.e. a positive effect on the functioning of cohabiting species (Ammer 2017; Anderegg et al. 2018, Grossiord 2019; Schnabel et al. 2019; Fichtner et al. 2020). According to our model, neighbourhood interspecific interactions played an important role for the survival of trees, either mitigating or enhancing drought stress depending on the surrounding species. This might explain controversial reports of species-mixing effects on drought stress. We used a modified competition index based on Hegyi (1974) to describe the effect of the relative height of each of the eight immediate neighbour trees on the probability of death of the focal tree (Fig. S1.1) while accounting for all possible inter- and intraspecific pairs of neighbour species constellations. We observed a negative neighbourhood effect on the risk of mortality for the majority of focal tree species 


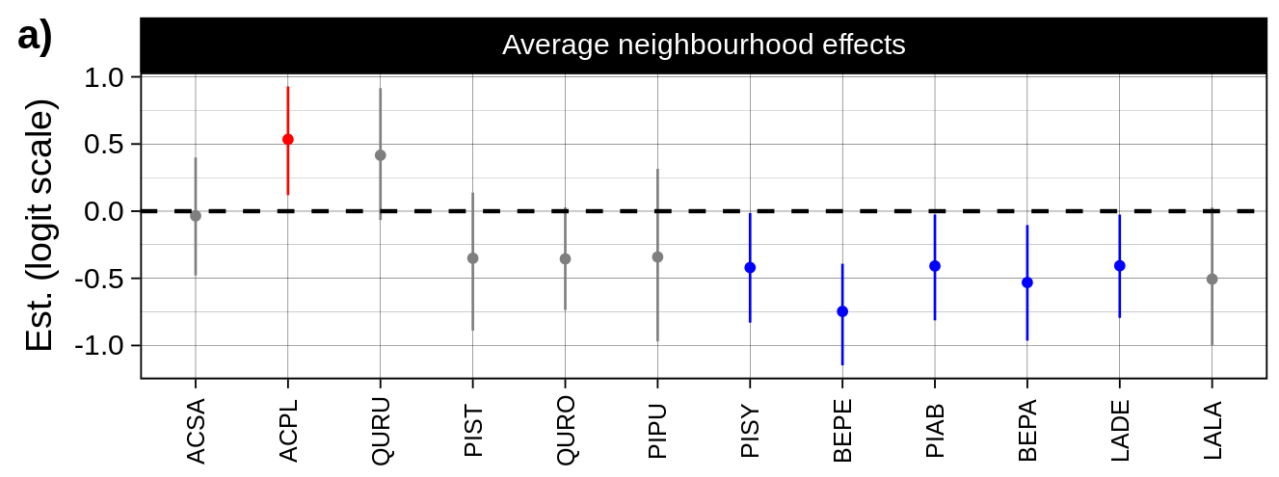

b)

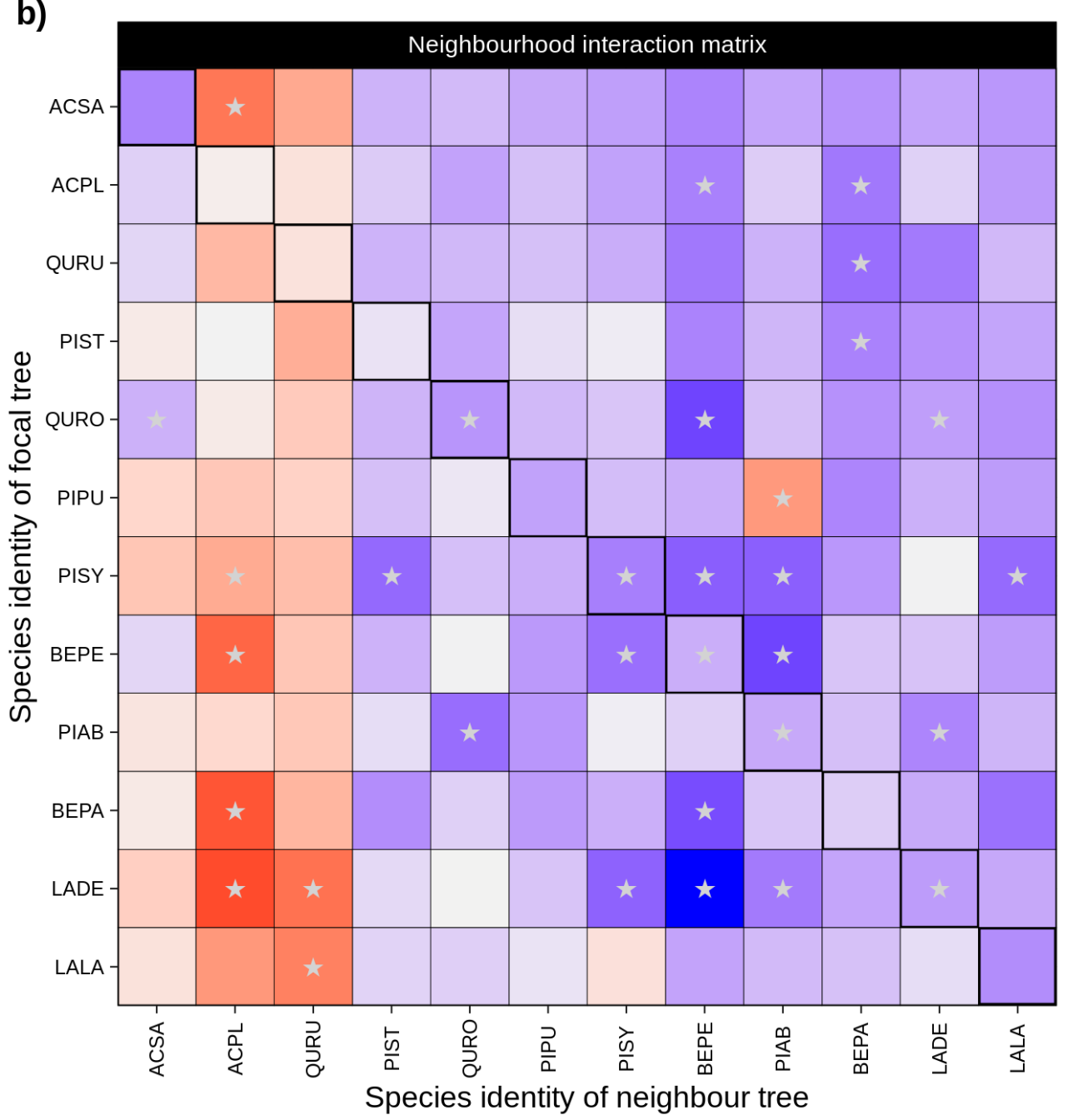

Neighbour effect

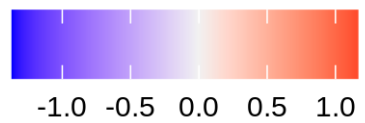

Fig. 5. a) Estimated average neighbourhood effect on mortality on the logit scale (posterior mean $\pm 95 \%$ HDI). Blue: credibly reduced risk; red: credibly elevated risk; grey: no credible effect on mortality. b) Full matrix of the neighbourhood effects of a given species (columns) on focal trees of a given species (rows) on the logit scale. Colours indicate the strength of the effect; stars indicate effects that are credibly different from zero at the $95 \%$ level. The highlighted panels on the plot diagonal show intra-specific neighbourhood effects. Species are ordered by increasing mortality. For species acronyms, see Table 1 . 
(Fig. 5a). The number of neighbours of a particular species surrounding each focal tree varied depending on the species mixture in the plot and pre-drought background mortality. The presence of more and larger neighbours of a given species resulted in a reduced mortality risk in the majority of possible combinations. A. platanoides was the only species whose presence on average increased the mortality risk of its neighbours (Fig. 5a). Across pairs of tree species, beneficial interactions were much more common than detrimental ones (Fig. 5b). The correlation between the directed neighbourhood effects in a pair of neighbours was not credibly different from zero $\left(\rho_{\gamma}=-0.25,95 \%\right.$ HDI: $\left.-0.76-0.22\right)$, indicating that an advantage for one species in a pair did not always translate into a disadvantage for its neighbour. Instead, there was a tendency of pairs of neighbour species to be either one-sided or mutually beneficial, while not a single combination resulted in an increased mortality risk for both species (Fig. S2.4). In general, species that suffered more from drought increased the survival probability of their neighbours and vice versa. While A. platanoides, the species that most strongly increased the mortality of its neighbours, was among the species least affected by drought, four of the five species with positive effects on the survival of their neighbours suffered losses of over $50 \%$ (Fig. 1, Fig. 5a, Table 1). Besides an increased mortality of P. pungens in the neighbourhood of $P$. abies, the only species that reduced the survival of their neighbours were A. platanoides and $Q$. rubra. The presence of these two dominant overstory species increased the mortality especially for suppressed, subordinate species (Fig. 5). The increased survival of trees with neighbour species that suffered extreme losses may be a result of competitive release, especially in the case of Larix spp. and Betula spp., which did not compete for water after their early leaf shedding in 2018.

An important implication of our model is that drought-related interactions between neighbouring trees are directed and species-specific, as previously observed for adult trees (Forrester et al. 2016). Studies of mitigation and competition tend to focus on effects of species richness (e.g. Fichtner et al. 2020), which integrate over all possible neighbourhood 
interactions. However, a net positive effect of species richness on survival only occurs if the interspecific neighbourhood interactions on average are more beneficial than intraspecific interactions. Whether or not there is a positive relationship with species richness therefore depends on the identity of the studied species rather than their mere number. Methods that preserve the information about the identity of interacting species allow for a more nuanced understanding of the underlying processes, and provide valuable additional information that e.g. permits identification of mutually beneficial species combinations. We hope that our approach to addressing neighbourhood effects contributes to a more thorough focus on the nature of directed neighbourhood interactions in plant drought responses, as in their sum they ultimately determine the resilience of a community against drought events.

\section{Nutrient and environmental effects}

Conditional on the effect of the other predictor variables, none of the nutrient-enhanced treatments (N, P or NP addition) differed in mortality compared to the control treatment for any of the analysed species (Fig. 3, Fig. S2.2). Limitations posed by the design of the IDENT experiment preclude a clear interpretation of the nutrient effects, as fertilizer was only applied to the subset of European species, but not to the North-American ones, and several highly relevant species-level traits were only measured on the control treatment. So far, only a limited number of studies are available for the interaction between drought and plant nutrition and the role of nutrients in drought-induced mortality (Royo \& Knight 2012; Wang et al. 2012; Sergent et al. 2014; Gessler et al. 2017). However, fertilization can reasonably be assumed to affect tree size, hydraulic efficiency and safety (Zhang et al. 2018), carbon dynamics (Li et al. 2018; Schönbeck et al. 2020) and susceptibility to bark beetles (Herms 2002), as well as other potential unmeasured predictors of mortality. The main rationale for including nutrient effects in our model was therefore not to accurately estimate their total effect on mortality, but to control for potential confounding effects (see Supplementary Material S1). 
While no direct fertilization effects were observed, a considerable amount of the species-wise plot effects were credibly different from zero (Fig. S2.5), indicating the presence of small-scale environmental influences on tree survival. Though the precise origin of these differences is unknown, our results indicate they had a non-negligible contribution to the total variance in mortality risk, which may be associated with plot-specific differences, e.g. in soil texture, rooting depth or wind exposition.

\section{Conclusions}

The extreme natural drought event in 2018 that killed over one third of the trees at the IDENT tree diversity experiment in Freiburg provided a unique opportunity to compare the mutually inclusive mechanisms underlying drought-induced mortality in one setting. While we support the view that severe tissue dehydration causing hydraulic failure marks the final stage in the process of tree death under drought, our results illustrate that hydraulic traits alone are not sufficient to predict individual mortality risk. Instead, the individual probability of reaching lethal desiccation thresholds depends on a series of mutually inclusive processes, notably starch depletion, known to be important for osmotic adjustment. Given the projected increase in drought exposure in most of the world's forested biomes, improving the mechanistic understanding of processes involved in drought-induced tree mortality is essential. To predict future changes in the structure and composition of forests, it is crucial to adopt a holistic view on the drivers of tree death under drought. Specifically, there is a need for an improved understanding of the processes that link carbohydrate metabolism and water relations, and the ways mortality risk is modulated by pests, environmental conditions, and neighbourhood interactions among trees varying in size and species composition in a non-zero-sum list of effects. 


\section{Methods}

\section{Site description}

The dataset for this study was collected in 2018/19 at the International Diversity Experiment Network with Trees (IDENT) in Freiburg, Germany (4801'10"N, 749'37"E; 240 m a.s.1) (Tobner et al. 2014; Wein et al. 2016). IDENT belongs to the global network of tree diversity experiments (TreeDivNet, Paquette et al. 2018). Mean annual temperature was $11.6^{\circ} \mathrm{C}$ and mean annual precipitation $881.8 \mathrm{~mm}$ (long-term average from 1989-2019). Similar to the exceptional hot and dry conditions in large parts of Central Europe in 2018 (Hari et al. 2020; Schuldt et al. 2020), the IDENT study site was subjected to the most severe summer drought ever recorded in the region. The mean temperature from June to August in 2018 were $2.0^{\circ} \mathrm{C}$ above $\left(20.9\right.$ vs. $\left.18.9^{\circ} \mathrm{C}\right)$ and precipitation rates $62 \%$ below $(118.2$ vs. $314.2 \mathrm{~mm})$ the long-term average from 1961-1990, respectively (DWD Climate Data Centre - CDC 2020a, b).

The study site comprises 415 plots of $13 \mathrm{~m}^{2}$, each containing $7 \times 7=49$ trees planted on a $0.45 \times 0.45 \mathrm{~m}^{2}$ grid, resulting in a total of 20,335 trees. A buffer zone of $0.9 \mathrm{~m}$ separates neighbouring plots. The experiment manipulates tree diversity (richness,: monocultures and two, four, six species; functional diversity: mixtures of varying similarity in selected functional traits), geographic origin (European, North American), and species composition (different species mixtures per diversity level) in a four-times replicated block design using a species pool of six congeneric species pairs native to North America and Europe (Table 1). Mixtures comprising European species (with the exception of 6-species mixtures) were replicated for a tree species richness $\mathrm{x}$ fertilization sub-experiment with nitrogen (130 g elemental $\mathrm{N}$ per plot), phosphorous (65 g elemental P per plot) and N+P addition, respectively. All trees were planted in 2013 as 1-3 years old saplings on shallow sandy-loamy Cambisol (0.4 m) with a high gravel content bedrock $(1.0 \mathrm{~m})$. 


\section{Tree mortality and height}

We surveyed the survival and health status of all 20,335 planted trees at pre-drought $(2017 / 18$ inventory), directly after the drought in autumn 2018, and post-drought in early summer of 2019. Trees were classified as healthy, damaged (leaf browning or leaf loss), severely damaged (partial canopy dieback) or dead. Our analysis was based on the subset of the inner 25 trees of each plot that were alive during the pre-drought inventory, resulting in a total of 9,435 trees. These trees represent $90.9 \%$ of the initially planted individuals. Since boreholes of the bark beetle Pityogenes chalcographus were observed on several trees in early July 2018, we additionally recorded the beetle infestation for all conifers.

Pre-drought tree height (stem base to the apical branch) was measured during December 2017 and January 2018 for the 25 central trees of each plot as part of a yearly inventory. Additionally, a remote sensing campaign was carried out in July 2018 using a drone (Octo8XL, Mikrokopter GmbH, Saldenburg, Germany) equipped with an optical RGB camera with a $16 \mathrm{~mm}$ lens (Sony A5000, Stuttgart, Germany). The heights of the edge trees (for computation of neighbourhood effects) were then imputed based on these remote-sensing derived aggregate and rescaled by the average height of the corresponding species in each plot to account for species differences (see Supplementary Material S1 for details).

\section{Hydraulic traits}

For measuring xylem embolism resistance, $100-150 \mathrm{~cm}$ long branch samples were collected from 12-19 live trees per species with the exception of the genus Quercus (3-5 trees $\times 4$ plots $\times 10$ species $=171$ samples in total) in late summer 2019 , immediately wrapped in moist towels and stored in black plastic bags to prevent dehydration during transport. Samples were re-cut under water directly before xylem vulnerability curves were constructed according to standard protocols for short-vesseled coniferous and diffuse-porous species using the flow-centrifuge technique (Cochard et al. 2005; Delzon et al. 2010; Schuldt et al. 2016). Vulnerability curves 
were fitted in R v4.0.0 (R Core Team 2020) with nonlinear least squares using a sigmoidal model based on the raw conductance measurements (Pammenter \& Vander Willigen 1998; Ogle et al. 2009) (see details in Supplementary Material 1). Values for the long-vessel Quercus species were obtained from published data (Lobo et al. 2018).

Midday leaf water potential $\left(\Psi_{\mathrm{md}}, \mathrm{MPa}\right)$ was measured for four trees per species in all 48 monocultures at the peak of the drought (12-14 August) using a Scholander pressure chamber (1505D-EXP, PMS Instruments, Corvallis, USA).

Hydraulic safety margins (HSM) were computed as the difference between $\Psi_{\mathrm{md}}$ and averages of the critical xylem pressure $\left(P_{\text {crit }}\right)$, which was assumed to be equivalent to the pressure at $88 \%$ loss of conductivity for angiosperms and 50\% for conifers (Brodribb \& Cochard 2009; Urli et al. 2013; Delzon \& Cochard 2014). To account for the uncertainty in the estimated vulnerability curve parameters, it was propagated into the calculated HSM values (see Supplementary Material S1 for details).

\section{Non-structural carbohydrates}

Leaf samples for the analysis of non-structural carbohydrate contents were taken during predrought (21 May to 18 June 2018) after leaf enfolding was completed in monocultures (48 plots), and post-drought (1-4 October 2018) on the full design, yielding 1,000 sampled trees in total. Leaves were sampled from a random subset of the inner $5 \times 5$ trees representing the most common tree size whenever possible. Buffer trees were sampled if less than three trees per species were available for sampling in the core area. Each three to five leaves or 50-100 needles from a vital branch of the upper and middle part of the sun canopy were pooled, immediately stored at $4^{\circ} \mathrm{C}$ in the field and, within the same day, oven-dried at $60^{\circ} \mathrm{C}$ for $48 \mathrm{~h}$ to stop enzymatic activity (Landhäusser et al. 2018).

The low-molecular-weight sugars (glucose, fructose and sucrose) and starch were analyzed following the protocol of Wong (1990), modified according to Hoch et al. (2002) (see 
Supplementary Material S1 for details). The change in relative sugar content (i.e. in the relative contribution of soluble sugars to the total non-structural carbohydrates) over the growing season $\left(\Delta_{\text {sugar }}\right)$ was then calculated as the difference in the percentage of soluble sugars measured in May and in October 2018 in 48 unfertilized plots in the monocultures. The change in relative sugar content is expected to act as an indicator for the amount of starch-to-sugar conversion and depletion of starch reserves over the growing season (He et al. 2020).

\section{Neighbourhood effects}

The influence of up to eight immediate neighbour trees on each of $i$ in $I$ central trees was expressed in form of a $I \times J$ neighbourhood matrix $N$ containing the sum of the heights $h_{j}$ of the trees of species $j$ of $J$ species divided by the height $h_{i}$ of the central tree, weighted by their relative distance $d_{i j}$ (i.e. with a weight of 1 for first and $1 / \sqrt{2}$ for second order neighbours; see Supplementary Material S1).

$$
N_{i j}=\sum \frac{h_{j}}{h_{i} d_{i j}}
$$

In this formulation, the computed value can be interpreted as a partial Hegyi competition index for a species (Hegyi, 1974), thus effectively decomposing the contribution of different competitor species to the total neighbourhood effect.

\section{Statistical modelling}

In a hierarchical Bayesian modelling framework based on the Stan probabilistic programming language (Stan v. 2.21.0; Carpenter et al. 2017), we described the observed tree mortality status in 2019 as a function of the individual mortality risk.

We assumed that the observed state of a tree $\left(Y_{o b s[i j k]} ; 0\right.$ : tree alive, 1: tree dead $)$ for each tree $i$ belonging to species $j$ in plot $k$ for a total of $I$ trees, $J$ species and $K$ plots is subject to observation errors with a species-specific probability of erroneously classifying a living tree as 
dead (e.g. because of leaf shedding). To account for this misclassification, we modelled the observed mortality state of individual trees as a one-inflated Bernoulli process with a treespecific probability of dying $p_{i j k}$ and a species-specific misclassification probability $\phi_{j}$.

$$
\begin{aligned}
& \operatorname{Pr}\left(Y_{o b s[i j k]}=0 \mid p_{i j k}, \phi_{j}\right)=\left(1-\phi_{j}\right) \cdot\left(1-p_{i j k}\right) \\
& \operatorname{Pr}\left(Y_{o b s[i j k]}=1 \mid p_{i j k}, \phi_{j}\right)=\phi_{j}+\left(1-\phi_{j}\right) \cdot\left(1-p_{i j k}\right)
\end{aligned}
$$

We further included observation models for the two species level traits in the focus of our main hypotheses, namely the hydraulic safety margin HSM and the shift in the fraction of soluble sugars of the total leaf non-structural carbohydrate content ( $\left.\Delta_{\text {sugar }}\right)$ (see details in Supplementary Material S1).

We expressed the probability of dying $p_{i j k}$ of each tree as a logit-linear function of the true species-level $\Delta_{\text {sugar }}$ and $H S M$ values, a term specifying species specific intercept and effects of tree height, bark beetle infestation and nutrient treatment $(I \times L$ predictor matrix $\boldsymbol{X})$, a term specifying neighbourhood effects $(I \times J$ neighbourhood matrix $N$, elevated to a power of $c)$, and species-specific plot effects $\delta_{j k}$.

$$
\operatorname{logit}\left(p_{i j k}\right)=H S M_{\text {true }[j]} \cdot \alpha_{H S M}+\Delta s u g a r_{\text {true }[j]} \cdot \alpha_{\Delta_{\text {sugar }}}+X_{i} \beta_{j}+N_{i}^{c} \gamma_{j}+\delta_{j k}
$$

The $J \times L$ species-specific regression coefficients $\boldsymbol{\beta}$ were described by a multivariate normal distribution with covariance matrix $\Sigma_{\beta}$ :

$\beta_{j} \sim \operatorname{MVN}\left(\beta_{0}, \Sigma_{\beta}\right)$

To account for a possible correlation between the directed neighbourhood effects within a pair of species, the $J \times J$ neighbourhood effects matrix $\gamma$ for focal species $m$ and neighbour species $n$ was parameterized as follows:

$$
\begin{array}{ll}
\left(\begin{array}{l}
\gamma_{m, n} \\
\gamma_{n, m}
\end{array}\right) \sim \operatorname{MVN}\left(\left(\begin{array}{l}
\gamma_{0[n]} \\
\gamma_{0[m]}
\end{array}\right), \tau_{\gamma}^{2} \Omega_{\gamma}\right) & \text { for all } \gamma \text { with } m \neq n \\
\gamma_{m, n} \sim \operatorname{Normal}\left(\gamma_{0[n]}, \tau_{\gamma}\right) & \text { for all } \gamma \text { with } m=n
\end{array}
$$


where $\Omega_{\gamma}$ is a $2 \times 2$ correlation matrix allowing for a correlation of the directed neighbourhood effects in pairs of non-identical species (the off-diagonal elements of $\gamma$ ).

The design effects $\delta$ for each plot and species were modelled by a normal distribution centred around zero with standard deviation $\tau_{\delta}$, i.e. as a varying intercept for each combination of plot and species:

$\delta_{j k} \sim \operatorname{Normal}\left(0, \tau_{\delta}\right)$

Modelling was performed via R using rstan v. 2.19.3 (Stan Development Team, 2020). The model reached a $\hat{R}$ statistic of under 1.002 and effective sample sizes above 1,500 for all estimated parameters, indicating full model convergence (Table S2.1). The estimated speciesspecific misclassification rates $\phi$ were low (on average 0.9\%; Supplementary Material S1), though higher rates of up to $4.2 \%$ of trees erroneously classified as dead were found for some species (Table S2.1, Fig. S2.1), resulting in a visible mismatch between observed and predicted mortality for these species in Fig. 1. Details about model structure, prior specification, model implementation and model fitting are provided in Supplementary Material S1. The model code and raw data are available as a repository on Github (Supplementary Material S3). 


\section{Acknowledgements}

We thank C. Gernert, Y. Heppenstiel, B. Kukatsch, S. Ouyang and L. Schönbeck for their support in the laboratories and S. Bilodeau-Gauthier, A. Böminghaus, G. Csapek, A.-L. Hillebrecht, A. Klingler, D. Saito, A. Schäfer, D. Sprenger, M. Romer, M. Ulmerich, J. Maron and M. Witt for their contribution to data collection at IDENT Freiburg. Funding by the German Research Foundation (DFG 384026712 to LR; DFG 316733524 to CN) and the University of Freiburg (Innovationsfonds Forschung to MSL and JB) is gratefully acknowledged. The research presented here contributes to the International Tree Mortality Network (https://www.tree-mortality.net/), an initiative of the IUFRO Task Force on Tree Mortality (https://www.iufro.org/science/task-forces/tree-mortality-patterns/), and to the Global Network of Tree Diversity Experiments (TreeDivNet; https://treedivnet.ugent.be/), belonging to the IDENT network within TreeDivNet.

\section{Author contributions}

A.P. and C.M. developed the original IDENT design. M.S.-L. and. J.B. expanded and implemented the design for the Freiburg trial and maintained it together with C.N. and T.G.. L.R., B.S. and A.G. developed the presented study. C.N. was responsible for pre-drought inventories, P.H. performed the mortality inventory and field sampling with support from L.R., and K.K. provided drone derived tree heights. P.H. performed all physiological measurements with support from M.S.. R.M.L. developed the model and performed the statistical analyses, and P.H., R.M.L. and B.S. wrote the first version of the manuscript, which was intensively discussed and revised by all authors.

\section{Competing interests}

The authors declare no competing interests. 


\section{Supplementary material}

\section{S1: $\quad$ Supplementary methods}

S2: $\quad$ Supplementary results

S3: Digital supplement: A repository containing the code for data processing and fitting the model described in S1 and the full dataset is available upon request and will be made public after publication of the article under the following address:

https://github.com/r-link/mutually_inclusive_mechanisms 


\section{References}

Adams HD, Zeppel MJB, Anderegg WRL, Hartmann H, Landhäusser SM, Tissue DT, Huxman TE, Hudson PJ, Franz TE, Allen CD, et al. 2017. A multi-species synthesis of physiological mechanisms in drought-induced tree mortality. Nature Ecology \& Evolution 1: 1285-1291.

Allen CD, Breshears DD, McDowell NG 2015. On underestimation of global vulnerability to tree mortality and forest die-off from hotter drought in the Anthropocene. Ecosphere 6: 1-55.

Ammer C. 2017. Unraveling the Importance of Inter- and Intraspecific Competition for the Adaptation of Forests to Climate Change. In: Cánovas FM, Lüttge U, Matyssek R, eds. Progress in Botany. Progress in Botany Vol. 78. Cham: Springer International Publishing, 345-367.

Ammer C. 2019. Diversity and forest productivity in a changing climate. New Phytologist 221: 50-66.

Anderegg WRL, Klein T, Bartlett M, Sack L, Pellegrini AFA, Choat B, Jansen S. 2016. Metaanalysis reveals that hydraulic traits explain cross-species patterns of drought-induced tree mortality across the globe. Proceedings of the National Academy of Sciences 113: 5024-5029.

Anderegg WRL, Konings AG, Trugman AT, Yu K, Bowling DR, Gabbitas R, Karp DS, Pacala S, Sperry JS, Sulman BN, et al. 2018. Hydraulic diversity of forests regulates ecosystem resilience during drought. Nature 561: 538-541.

Atkin OK, Macherel D. 2009. The crucial role of plant mitochondria in orchestrating drought tolerance. Annals of Botany 103: 581-597.

Bennett AC, McDowell NG, Allen CD, Anderson-Teixeira KJ. 2015. Larger trees suffer most during drought in forests worldwide. Nature Plants 1: 15139.

Blackman CJ, Li X, Choat B, Rymer PD, De Kauwe MG, Duursma RA, Tissue DT, Medlyn BE. 2019. Desiccation time during drought is highly predictable across species of Eucalyptus from contrasting climates. New Phytologist 224: 632-643.

Blackman CJ, Pfautsch S, Choat B, Delzon S, Gleason SM, Duursma RA. 2016. Toward an index of desiccation time to tree mortality under drought. Plant, Cell \& Environment 39: 2342-2345.

Brodribb TJ, Cochard H. 2009. Hydraulic Failure Defines the Recovery and Point of Death in WaterStressed Conifers. Plant Physiology 149: 575-584.

Brodribb TJ, Powers J, Cochard H, Choat B. 2020. Hanging by a thread? Forests and drought. Science 368: 261-266.

Cailleret M, Jansen S, Robert EMR, Desoto L, Aakala T, Antos JA, Beikircher B, Bigler C, Bugmann H, Caccianiga M, et al. 2017. A synthesis of radial growth patterns preceding tree mortality. Global Change Biology 23: 1675-1690.

Carminati A, Javaux M. 2020. Soil rather than xylem vulnerability controls stomatal response to drought. Trends in Plant Science: S1360138520301187.

Carpenter B, Gelman A, Hoffman MD, Lee D, Goodrich B, Betancourt M, Brubaker M, Guo J, Li P, Riddell A. 2017. Stan: A Probabilistic Programming Language. Journal of Statistical Software 76.

Castagneyrol B, Jactel H, Moreira X. 2018. Anti-herbivore defences and insect herbivory: Interactive effects of drought and tree neighbours. Journal of Ecology 106: 2043-2057.

Charrier G, Torres-Ruiz JM, Badel E, Burlett R, Choat B, Cochard H, Delmas CEL, Domec J-C, Jansen S, King A, et al. 2016. Evidence for Hydraulic Vulnerability Segmentation and Lack of Xylem Refilling under Tension. Plant Physiology 172: 1657-1668.

Choat B, Brodribb TJ, Brodersen CR, Duursma RA, López R, Medlyn BE. 2018. Triggers of tree mortality under drought. Nature 558: 531-539.

Choat B, Nolf M, Lopez R, Peters JMR, Carins-Murphy MR, Creek D, Brodribb TJ. 2019. Non- 
invasive imaging shows no evidence of embolism repair after drought in tree species of two genera. Tree Physiology 39: 113-121.

Cochard H, Damour G, Bodet C, Tharwat I, Poirier M, Améglio T. 2005. Evaluation of a new centrifuge technique for rapid generation of xylem vulnerability curves. Physiologia Plantarum 124: $410-418$.

Correia DLP, Bouchard M, Filotas É, Raulier F. 2019. Disentangling the effect of drought on stand mortality and productivity in northern temperate and boreal forests. Journal of Applied Ecology 56: $758-768$.

Crouchet SE, Jensen J, Schwartz BF, Schwinning S. 2019. Tree Mortality After a Hot Drought: Distinguishing Density-Dependent and -Independent Drivers and Why It Matters. Frontiers in Forests and Global Change 2.

Dai A. 2013. Increasing drought under global warming in observations and models. Nature Climate Change 3: 52-58.

Dai Y, Wang L, Wan X. 2018. Relative contributions of hydraulic dysfunction and carbohydrate depletion during tree mortality caused by drought. AoB PLANTS 10: 1-17.

Delzon S, Cochard H. 2014. Recent advances in tree hydraulics highlight the ecological significance of the hydraulic safety margin. New Phytologist 203: 355-358.

Delzon S, Doute Cy, Sala A, Cochard H. 2010. Mechanism of water-stress induced cavitation in conifers: bordered pit structure and function support the hypothesis of seal capillary-seeding. Plant, Cell \& Environment 33: 2101-2111.

Duan H, Li Y, Xu Y, Zhou S, Liu J, Tissue DT, Liu J. 2019. Contrasting drought sensitivity and postdrought resilience among three co-occurring tree species in subtropical China. Agricultural and Forest Meteorology 272-273: 55-68.

Duursma RA, Blackman CJ, Lopéz R, Martin-StPaul NK, Cochard H, Medlyn BE. 2019. On the minimum leaf conductance: its role in models of plant water use, and ecological and environmental controls. New Phytologist 221: 693-705.

DWD Climate Data Center - CDC 2020a. Daily station observations of mean temperature at 2 $\mathrm{m}$ above ground in ${ }^{\circ} \mathrm{C}$ for Germany, version v19.3, last accessed: 2020-10-05

DWD Climate Data Center - CDC 2020b. Daily station observations precipitation height in mm for Germany, version v19.3, last accessed: 2020-10-05

Fichtner A, Härdtle W, Li Y, Bruelheide H, Kunz M, Oheimb G von. 2017. From competition to facilitation: how tree species respond to neighbourhood diversity. Ecology Letters 20: 892-900.

Fichtner A, Schnabel F, Bruelheide H, Kunz M, Mausolf K, Schuldt A, Härdtle W, Oheimb G. 2020. Neighbourhood diversity mitigates drought impacts on tree growth (F Gilliam, Ed.). Journal of Ecology 108: 865-875.

Forrester D, Bonal D, Dawud S, Gessler A, Granier A, Pollastrini M, Grossiord C. 2016. Drought responses by individual tree species are not often correlated with tree species diversity in European forests. Journal of Applied Ecology 53: 1725-1734

Gessler A, Schaub M, McDowell NG. 2017. The role of nutrients in drought-induced tree mortality and recovery. New Phytologist 214: 513-520.

Grossiord C. 2019. Having the right neighbors: how tree species diversity modulates drought impacts on forests. New Phytologist.

Grote R, Gessler A, Hommel R, Poschenrieder W, Priesack E. 2016. Importance of tree height and social position for drought-related stress on tree growth and mortality. Trees 30: 1467-1482.

Hari V, Rakovec O, Markonis Y, Hanel M, Kumar R. 2020. Increased future occurrences of the exceptional 2018-2019 Central European drought under global warming. Scientific reports 10: 110 
Hart SJ, Veblen TT, Eisenhart KS, Jarvis D, Kulakowski D. 2014. Drought induces spruce beetle (Dendroctonus rufipennis) outbreaks across northwestern Colorado. Ecology 95: 930-939.

Hartmann H, Schuldt B, Sanders TGM, Macinnis-Ng C, Boehmer HJ, Allen CD, Bolte A, Crowther TW, Hansen MC, Medlyn BE, et al. 2018. Monitoring global tree mortality patterns and trends. Report from the VW symposium 'Crossing scales and disciplines to identify global trends of tree mortality as indicators of forest health'. New Phytologist 217: 984-987.

Hartmann H, Ziegler W, Kolle O, Trumbore S. 2013. Thirst beats hunger - declining hydration during drought prevents carbon starvation in Norway spruce saplings. New Phytologist 200: 340-349.

He W, Liu H, Qi Y, Liu F, Zhu X. 2020. Patterns in nonstructural carbohydrate contents at the tree organ level in response to drought duration. Global Change Biology 26: 3627-3638.

Hegyi F. 1974. A simulation model for managing jack-pine stands. In: Fries J, ed. Growth models for tree and stand simulation. Stockholm, Sweden: Royal College of Forestry, 74-90.

Herms DA. 2002. Effects of Fertilization on Insect Resistance of Woody Ornamental Plants: Reassessing an Entrenched Paradigm. Environmental Entomology 31: 923-933.

Hoch G, Popp M, Korner C. 2002. Altitudinal increase of mobile carbon pools in Pinus cembra suggests sink limitation of growth at the Swiss treeline. Oikos 98: 361-374.

Hsiao TC, Acevedo E, Fereres E, Henderson DW 1976. Water stress, growth and osmotic adjustment. Philosophical Transactions of the Royal Society of London. B, Biological Sciences 273: 479-500.

Huang J, Kautz M, Trowbridge AM, Hammerbacher A, Raffa KF, Adams H D, et al. 2020. Tree defence and bark beetles in a drying world: carbon partitioning, functioning and modelling. New Phytologist 225: 26-36.

Kannenberg SA, Phillips RP. 2020. Non-structural carbohydrate pools not linked to hydraulic strategies or carbon supply in tree saplings during severe drought and subsequent recovery. Tree Physiology 40: 259-271.

Klein T, Zeppel MJB, Anderegg WRL, Bloemen J, De Kauwe MG, Hudson P, Ruehr NK, Powell TL, von Arx G, Nardini A. 2018. Xylem embolism refilling and resilience against droughtinduced mortality in woody plants: processes and trade-offs. Ecological Research 33: 839-855.

Kohyama T. 1994. Size-structure-based models of forest dynamics to interpret population- and community-level mechanisms. Journal of Plant Research 107: 107-116.

Landhäusser SM, Chow PS, Dickman LT, Furze ME, Kuhlman I, Schmid S, Wiesenbauer J, Wild B, Gleixner G, Hartmann H, et al. 2018. Standardized protocols and procedures can precisely and accurately quantify non-structural carbohydrates. Tree Physiology 38: 1764-1778.

Ledo A, Paul KI, Burslem DFRP, Ewel JJ, Barton C, Battaglia M, Brooksbank K, Carter J, Eid TH, England JR, et al. 2018. Tree size and climatic water deficit control root to shoot ratio in individual trees globally. New Phytologist 217: 8-11.

Li W, Hartmann H, Adams HD, Zhang H, Jin C, Zhao C, Guan D, Wang A, Yuan F, Wu J. 2018. The sweet side of global change-dynamic responses of non-structural carbohydrates to drought, elevated CO2 and nitrogen fertilization in tree species. Tree Physiology 38: 1706-1723.

Li X, Piao S, Wang K, Wang X, Wang T, Ciais P, Chen A, Lian X, Peng S, Peñuelas J. 2020. Temporal trade-off between gymnosperm resistance and resilience increases forest sensitivity to extreme drought. Nature Ecology \& Evolution 4: 1075-1083.

Lindenmayer DB, Laurance WF, Franklin JF. 2012. Global Decline in Large Old Trees. Science 338: $1305-1306$.

Lobo A, Torres-Ruiz JM, Burlett R, Lemaire C, Parise C, Francioni C, Truffaut L, Tomášková I, Hansen JK, Kjær ED, et al. 2018. Assessing inter- and intraspecific variability of xylem vulnerability to embolism in oaks. Forest Ecology and Management 424: 53-61. 
van Mantgem PJ, Stephenson NL, Byrne JC, Daniels LD, Franklin JF, Fule PZ, Harmon ME, Larson AJ, Smith JM, Taylor AH, et al. 2009. Widespread increase of tree mortality rates in the Western United States. Science 323: 521-524.

McDowell NG, Allen CD, Anderson-Teixeira K, Aukema BH, Bond-Lamberty B, Chini L, Clark JS, Dietze M, Grossiord C, Hanbury-Brown A, et al. 2020. Pervasive shifts in forest dynamics in a changing world. Science 368 : eaaz9463.

McDowell NG, Beerling DJ, Breshears DD, Fisher RA, Raffa KF, Stitt M. 2011. The interdependence of mechanisms underlying climate-driven vegetation mortality. Trends in Ecology \& Evolution 26: 523-532.

McDowell NG, Fisher RA, Xu C, Domec JC, Hölttä T, Mackay DS, Sperry JS, Boutz A, Dickman L, Gehres N, et al. 2013. Evaluating theories of drought-induced vegetation mortality using a multimodel-experiment framework. New Phytologist 200: 304-321.

McDowell NG, Brodribb TJ, Nardini A. 2019. Hydraulics in the $21^{\text {st }}$ century. New Phytologist 224: $537-542$.

McDowell N, Pockman WT, Allen CD, Breshears DD, Cobb N, Kolb T, Plaut J, Sperry J, West A, Williams DG, et al. 2008. Mechanisms of plant survival and mortality during drought: why do some plants survive while others succumb to drought? New Phytologist 178: 719-739.

McDowell NG, Sevanto S. 2010. The mechanisms of carbon starvation: how, when, or does it even occur at all? New Phytologist 186: 264-266.

Merchant A. 2014. The Regulation of Osmotic Potential in Trees. In: Tausz M, Grulke N, eds. Plant Ecophysiology. Trees in a Changing Environment: Ecophysiology, Adaptation, and Future Survival. Dordrecht: Springer Netherlands, 83-97.

Netherer S, Matthews B, Katzensteiner K, Blackwell E, Henschke P, Hietz P, Pennerstorfer J, Rosner S, Kikuta S, Schume H, et al. 2015. Do water-limiting conditions predispose Norway spruce to bark beetle attack? New Phytologist 205: 1128-1141.

O'Brien MJ, Engelbrecht BMJ, Joswig J, Pereyra G, Schuldt B, Jansen S, Kattge J, Landhäusser SM, Levick SR, Preisler Y, et al. 2017. A synthesis of tree functional traits related to droughtinduced mortality in forests across climatic zones (J Firn, Ed.). Journal of Applied Ecology 54: $1669-1686$.

O'Brien MJ, Valtat A, Abiven S, Studer MS, Ong R, Schmid B. 2020. The role of soluble sugars during drought in tropical tree seedlings with contrasting tolerances. Journal of Plant Ecology 13: 389-397.

Ogle K. 2009. Hierarchical Bayesian Statistics: Merging Experimental and Modeling Approaches in Ecology. Ecological Applications 19: 577-581.

Olson ME, Soriano D, Rosell JA, Anfodillo T, Donoghue MJ, Edwards EJ, León-Gómez C, Dawson T, Camarero Martínez JJ, Castorena M, et al. 2018. Plant height and hydraulic vulnerability to drought and cold. Proceedings of the National Academy of Sciences 115: 75517556.

Pammenter NW, Vander Willigen C. 1998. A mathematical and statistical analysis of the curves illustrating vulnerability of xylem to cavitation. Tree Physiology 18: 589-593.

Pantin F, Fanciullino A-L, Massonnet C, Dauzat M, Simonneau T, Muller B. 2013. Buffering growth variations against water deficits through timely carbon usage. Frontiers in Plant Science 4.

Paquette, A, Hector, A, Castagneyrol, B, Vanhellemont, M, Koricheva, J, Scherer-Lorenzen, M, Verheyen, K. 2018. A million and more trees for science. Nature Ecology \& Evolution 2: 763-766.

Peng C, Ma Z, Lei X, Zhu Q, Chen H, Wang W, Liu S, Li W, Fang X, Zhou X. 2011. A droughtinduced pervasive increase in tree mortality across Canada's boreal forests. Nature Climate Change 1: $467-471$. 
Phillips OL, van der Heijden G, Lewis SL, López-González G, Aragão LEOC, Lloyd J, Malhi Y, Monteagudo A, Almeida S, Dávila EA, et al. 2010. Drought-mortality relationships for tropical forests. New Phytologist 187: 631-646.

Powers JS, Vargas-G G, Brodribb TJ, Schwartz NB, Perez-Aviles D, Smith-Martin CM, Becknell JM, Aureli F, Blanco R, Calderón-Morales E, et al. 2020. A catastrophic tropical drought kills hydraulically vulnerable tree species. Global Change Biology n/a.

Pretzsch, H, \& Forrester, DI. 2017. Stand dynamics of mixed-species stands compared with monocultures. In: Pretzsch H, Forrester DI, Bauhus U, eds. Mixed-Species Forests. Springer, Berlin, Heidelberg. 117-209.

R Core Team. 2020. R: A language and environment for statistical computing. Vienna, Austria. URL: https://www.R-project.org/.

Raffa KF, Aukema BH, Bentz BJ, Carroll AL, Hicke JA, Turner MG, Romme WH. 2008. Crossscale drivers of natural disturbances prone to anthropogenic amplification: the dynamics of bark beetle eruptions. BioScience 58: 501-517.

Rehschuh R, Cecilia A, Zuber M, Faragó T, Baumbach T, Hartmann H, Jansen S, Mayr S, Ruehr N. 2020. Drought-Induced Xylem Embolism Limits the Recovery of Leaf Gas Exchange in Scots Pine. Plant Physiology 184: 852-864.

Rowland L, da Costa ACL, Galbraith DR, Oliveira RS, Binks OJ, Oliveira A a. R, Pullen AM, Doughty CE, Metcalfe DB, Vasconcelos SS, et al. 2015. Death from drought in tropical forests is triggered by hydraulics not carbon starvation. Nature 528: 119-122.

Royo AA, Knight KS. 2012. White ash (Fraxinus americana) decline and mortality: The role of site nutrition and stress history. Forest Ecology and Management 286: 8-15.

Ryan MG, Yoder BJ. 1997. Hydraulic Limits to Tree Height and Tree Growth. BioScience 47: 235242.

Sala A, Piper F, Hoch G. 2010. Physiological mechanisms of drought-induced tree mortality are far from being resolved. New Phytologist 186: 274-281.

Sapes G, Demaree P, Lekberg Y, Sala A. 2020. Plant carbohydrate depletion impairs water relations and spreads via ectomycorrhizal networks. New Phytologist, in press. doi:10.1111/nph.17134.

Schnabel F, Schwarz JA, Dănescu A, Fichtner A, Nock CA, Bauhus J, Potvin C. 2019. Drivers of productivity and its temporal stability in a tropical tree diversity experiment. Global Change Biology 25: 4257-4272.

Schönbeck L, Li M-H, Lehmann MM, Rigling A, Schaub M, Hoch G, Kahmen A, Gessler A. 2020. Soil nutrient availability alters tree carbon allocation dynamics during drought. bioRxiv: 2020.08.25.266205.

Schuldt B, Buras A, Arend M, Vitasse Y, Beierkuhnlein C, Damm A, Gharun M, Grams TEE, Hauck M, Hajek P, et al. 2020. A first assessment of the impact of the extreme 2018 summer drought on Central European forests. Basic and Applied Ecology 45: 86-103.

Schuldt B, Knutzen F, Delzon S, Jansen S, Müller-Haubold H, Burlett R, Clough Y, Leuschner C. 2016. How adaptable is the hydraulic system of European beech in the face of climate changerelated precipitation reduction? New Phytologist 210: 443-458.

Seidl R, Thom D, Kautz M, Martin-Benito D, Peltoniemi M, Vacchiano G, Wild J, Ascoli D, Petr M, Honkaniemi J, et al. 2017. Forest disturbances under climate change. Nature Climate Change 7: 395-402.

Senf C, Pflugmacher D, Zhiqiang Y, Sebald J, Knorn J, Neumann M, Hostert P, Seidl R. 2018. Canopy mortality has doubled in Europe's temperate forests over the last three decades. Nature Communications 9: 4978.

Sergent A-S, Rozenberg P, Bréda N. 2014. Douglas-fir is vulnerable to exceptional and recurrent 
drought episodes and recovers less well on less fertile sites. Annals of Forest Science 71: 697-708.

Sevanto S, Mcdowell NG, Dickman LT, Pangle R, Pockman WT. 2014. How do trees die? A test of the hydraulic failure and carbon starvation hypotheses. Plant, Cell \& Environment 37: 153-161.

Stan Development Team. 2020. RStan: the R interface to Stan. URL: http://mc-stan.org/.

Stovall AEL, Shugart H, Yang X. 2019. Tree height explains mortality risk during an intense drought. Nature Communications 10: 4385.

Stovall AEL, Shugart HH, Yang X. 2020. Reply to "Height-related changes in forest composition explain increasing tree mortality with height during an extreme drought". Nature Communications 11: 3401 .

Sturrock RN, Frankel SJ, Brown AV, Hennon PE, Kliejunas JT, Lewis KJ, Worrall JJ, Woods AJ. 2011. Climate change and forest diseases. Plant Pathology 60: 133-149.

Thalmann M, Santelia D. 2017. Starch as a determinant of plant fitness under abiotic stress. New Phytologist 214: 943-951.

Timofeeva G, Treydte K, Bugmann H, Rigling A, Schaub M, Siegwolf R, Saurer, M. 2017. Long-term effects of drought on tree-ring growth and carbon isotope variability in Scots pine in a dry environment. Tree Physiology 37: 1028-1041

Tobner, CM, Paquette, A, Reich, PB, Gravel, D, Messier, C 2014. Advancing biodiversityecosystem functioning science using high-density tree-based experiments over functional diversity gradients. Oecologia, 174: 609-621.

Trugman AT, Detto M, Bartlett MK, Medvigy D, Anderegg WRL, Schwalm C, Schaffer B, Pacala SW. 2018. Tree carbon allocation explains forest drought-kill and recovery patterns. Ecology Letters 21: 1552-1560.

Urli M, Porte AJ, Cochard H, Guengant Y, Burlett R, Delzon S. 2013. Xylem embolism threshold for catastrophic hydraulic failure in angiosperm trees. Tree Physiology 33: 672-683.

Vitali V, Forrester DI, Bauhus J. 2018. Know Your Neighbours: Drought Response of Norway Spruce, Silver Fir and Douglas Fir in Mixed Forests Depends on Species Identity and Diversity of Tree Neighbourhoods. Ecosystems 21: 1215-1229.

Wang W, Peng C, Kneeshaw DD, Larocque GR, Luo Z. 2012. Drought-induced tree mortality: ecological consequences, causes, and modeling. Environmental Reviews 20: 109-121.

Wein, A, Bauhus, J, Bilodeau-Gauthier, S, Scherer-Lorenzen, M, Nock, C, Staab, M. 2016. Tree species richness promotes invertebrate herbivory on congeneric native and exotic tree saplings in a young diversity experiment. PLoS One, 11: e0168751.

West GB, Brown JH, Enquist BJ. 1999. A general model for the structure and allometry of plant vascular systems. Nature 400: 664-667.

Wong S-C. 1990. Elevated atmospheric partial-pressure of $\mathrm{CO}_{2}$ and plant-growth. II: nonstructural carbohydrate content in cotton plants and its effect on growth-parameters. Photosynthesis Research 23: $171-180$.

Yuan W, Zheng Y, Piao S, Ciais P, Lombardozzi D, Wang Y, Ryu Y, Chen G, Dong W, Hu Z, et al. 2019. Increased atmospheric vapor pressure deficit reduces global vegetation growth. Science Advances 5: eaax1396.

Zhang H, Li W, Adams HD, Wang A, Wu J, Jin C, Guan D, Yuan F. 2018. Responses of woody plant functional traits to nitrogen addition: A Meta-Analysis of Leaf Economics, Gas Exchange, and Hydraulic Traits. Frontiers in Plant Science 9.

Zhou S, Zhang Y, Park Williams A, Gentine P. 2019. Projected increases in intensity, frequency, and terrestrial carbon costs of compound drought and aridity events. Science Advances 5: eaau5740. 